\title{
EFEKTIFITAS PERBANDINGAN PEMBERIAN MINUMAN DINGIN TERHADAP PENURUNAN SENSASI MUAL DAN MUNTAH SETELAH KEMOTERAPI PADA KLIEN KANKER PAYUDARA DI RS UMUM DR. H. ABDUL MOELOEK PROPINSI LAMPUNG
}

\author{
Dimas Ning Pangesti ${ }^{1}$, Yani Sofiani ${ }^{2}$ \\ ${ }^{1}$ Universitas Malahayati, ${ }^{2}$ Universitas Muhammadiyah Jakarta \\ Email: andoko2013@gmail.com
}

\begin{abstract}
Effectiveness study of Giving Cold Drinks to Decreased Sensation Nausea and Vomiting After Chemotherapy in the Breast Cancer Clients of General Hospital Dr.H. Abdul Moeloek, Lampung. More than $60 \%$ of clients who receive chemotherapy were complained of nausea and vomiting (King, 1997 in Mc Donald 2001). Based on interviews of four clients who had undergone chemotherapy at general hospital Dr.H.Abdul Moeloek, Lampung, nausea and vomiting cause reluctance to continue chemotherapy because it felt very excruciating. The aim of study was to determine the effectiveness of giving a cold drink to decrease the sensation of nausea and vomiting after chemotherapy in breast cancer client of public hospital Dr.H.Abdul Moeloek, Lampung. This research was quantitative, using a quasi-experimental research, pre and post test design. Total sample were 30 respondents. Data were analyzed by dependent t-test and ANOVA test. The results showed a difference sensation nausea and vomiting between before and after administration of sweet iced tea drinks, juice melon and ice cold milk Nutrican $10-15^{\circ} \mathrm{C}$ ( $\mathrm{p}$-value $=0.000$ ). It can be concluded that giving cold drinks $10-15^{\circ} \mathrm{C}$ can decrease the sensation of nausea and vomiting after chemotherapy in breast cancer clients of public hospital Dr.H.Abdul Moeloek, Lampung.
\end{abstract}

Keywords: Cold drinks $10-15^{\circ} \mathrm{C}$, nausea, vomiting, chemotherapy

\begin{abstract}
Abstrak: Efektifitas Perbandingan Pemberian Minuman Dingin terhadap Penurunan Sensasi Mual dan Muntah Setelah Kemoterapi pada Klien Kanker Payudara di RS Umum Dr.H. Abdul Moeloek Propinsi Lampung. Menurut King (1997, dalam Mc Donald, 2001) lebih dari $60 \%$ klien yang mendapat kemoterapi mengeluh adanya mual dan muntah. Berdasarkan wawancara terhadap 4 klien yang telah menjalani kemoterapi di RSU Dr.H.Abdul Moeloek, Lampung, rasa mual dan muntah menyebabkan rasa enggan untuk melanjutkan kemoterapi karena dirasakan sangat menyiksa. Tujuan penelitian, untuk mengetahui efektifitas perbandingan pemberian minuman dingin terhadap penurunan sensansi mual muntah setelah kemoterapi pada klien kanker payudara di RSU Dr.H.Abdul Moeloek, Lampung. Penelitian ini merupakan penelitian kuantitatif, menggunakan quasy experiment pre and post test design. Jumlah sampel 30 responden. Analisis statistik menggunakan uji t-test dependen dan uji Anova. Hasil uji statistik mual muntah sebelum dan sesudah pemberian minuman es teh manis, jus melon dan es susu nutrican dingin $10-15^{\circ} \mathrm{C}$ menunjukkan hasil uji $p$-value $=0,000$. Kesimpulan, terdapat pengaruh pemberian minuman dingin $10-15^{\circ} \mathrm{C}$ terhadap penurunan sensasi mual muntah setelah kemoterapi pada klien kanker payudara di RSU Dr.H.Abdul Moeloek, Lampung.
\end{abstract}

Kata Kunci: Minuman dingin $10-15^{\circ} \mathrm{C}$, mual muntah, kemoterapi

Kanker merupakan suatu penyakit yang dapat menyerang semua kalangan dari anak-anak hingga orang dewasa dan dapat tumbuh di semua jaringan tubuh. Sehingga diperlukan pengobatan salah satunya adalah kemoterapi. Setiap tahun jumlah klien kanker di dunia bertambah 6,25 juta orang. Setiap tahun, tercatat 100 klien kanker dari setiap 100.000 penduduk dan terdapat sekitar enam juta klien kanker baru pertahun. Dua pertiga dari klien kanker di dunia berada di negara-negara yang sedang berkembang termasuk Indonesia. Jumlah klien kanker di Indonesia mencapai enam persen dari populasi. Angka tersebut hampir sama dengan data di negara berkembang lainnya (Depkes, 2006).

Penelitian Simanjuntak dalam Hawari (2001), banyak faktor resiko yang menyebabkan terjadinya kanker payudara, diantaranya wanita berumur 25 tahun keatas, wanita yang tidak kawin, wanita yang memiliki anak pertama setelah usia 35 tahun, wanita yang mengalami menstruasi pertama pada usia kurang dari 12 
tahun, pernah mengalami penyinaran/radiasi serta mengalami masa menopause yang terlambat lebih dari 55 tahun dan masih banyak faktor-faktor lain terkait dengan gaya hidup wanita tersebut.

Efektifitas kemoterapi meskipun sering menjadi pilihan utama dalam mengatasi kanker, kemoterapi memiliki efek samping yang serius, dan yang paling sering dikeluhkan adalah mual dan muntah. King (1997, dalam Mc Donal, 2001) menyebutkan lebih $60 \%$ klien yang mendapat kemoterapi mengeluh adanya mual dan muntah.

Salah satu bentuk terapinya yaitu memberikan minuman dingin. Terapi nonfarmakologi berupa pemberian minuman dingin lebih cepat diserap dalam tubuh dari pada air hangat dan akan membantu rehidrasi, sehingga dapat mengupayakan klien agar merasa segar, membuka nafsu makan dan secara sadar dapat mengendalikan aktivitas faal dan psikis, memperbaiki kondisi disfungsi faal/psikis, sehingga berhasil menstabilkan emosi dan mengatasi gejala penyakitnya terutama keluhan mual muntah setelah kemoterapi. Minuman dingin dapat memiliki peran untuk memberikan kesegaran tubuh dan membuka nafsu makan. (Admin, 2012). Seperti dalam sebuah artikel tentang menggugah nafsu makan pada klien kanker, Dr. Erwin,C memberitahukan, hal lain yang dapat dilakukan klien kanker untuk mengatasi efek nafsu makan akibat kemoterapi yaitu dengan memilih makanan yang dingin, manis dan tidak beraroma. Biasanya dimulai dengan makanan yang dapat merangsang nafsu makan seperti es krim atau pop ice atau dengan tips memulai makan dengan makanan atau minuman yang dingin (Cristanto E,2012).

Tindakan nonfarmakologik salah satunya pemberian minuman dingin sebagai tindakan keperawatan yang spesifik untuk mengatasi mual dan muntah setelah kemoterapi belum tercantum dalam standar tindakan keperawatan di RSU.Dr .H.Abdul Moeloek Pripinsi Lampung.

Berdasarkan hal tersebut maka perlu dilaksanakan penelitian untuk mengidentifikasi efektifitas perbandingan pemberian minuman dingin $10-15^{\circ} \mathrm{C}$ dengan 3 jenis minuman (es teh manis, jus melon dan es susu) terhadap penurunan sensasi mual muntah setelah kemoterapi pada klien kanker payudara di Ruang Mawar RS Umum Dr. Hj. Abdul Moeloek Propinsi Lampung.

\section{METODE PENELITIAN}

Penelitian ini merupakan penelitian quasi experiment, yang merupakan penelitian sering digunakan dilapangan (Notoatmodjo; 2002). Disain ini tidak mempunyai pembatasan yang ketat terhadap randominasi, dan pada saat yang sama dapat mengontrol ancaman-ancaman validitas. Memfasilitasi pencarian hubungan sebab akibat dalam situasi dimana kontrol secara sempurna tidak memungkinkan dilakukan. Disain ini merupakan disain penelitian yang bertujuan menguji hubungan sebab akibat (Sastroasmoro \& Ismail, 2011; Polit \& Beck, 2006).

Penelitian ini menggunakan rancangan quasi experiment pre and post test yaitu suatu rancangan yang melakukan perlakuan pada dua atau lebih kelompok kemudian diobservasi sebelum dan sesudah implementasi (Polit \& Beck, 2006).

Populasi penelitian ini, semua klien dengan kanker payudara stadium II dan III yang menjalani kemoterapi pada siklus ke 3 di Ruang Mawar RS Umum dr.H.Abdul Moeloek Propinsi Lampung.

Tehnik pengambilan sampel dengan consecutive sampling, semua subyek yang datang dan memenuhi kriteria pemilihan dimasukan dalam penelitian sampai jumlah yang diperlukan terpenuhi (Sastroasmoro \& Ismael, 2011).

Sampel yang dipilih pada penelitian ini adalah yang memenuhi kriteria inklusi dan kriteria ekslusi yang telah ditetapkan sebagai subjek penelitian.

\section{HASIL}

\section{A. ANALISIS UNIVARIAT}

Diketahui bahwa tingkat pendidikan reponden untuk masing-masing kelompok intervensi sebagai berikut, kelompok es teh manis paling banyak berpendidikan SD, yaitu 7 klien (70\%) dan SMA 3 (30\%), kelompok jus melon responden pendidikan SD 6 klien (60\%), SMA 3 klien (30\%) dan PT 1 klien (10\%), kelompok es susu pendidikan SD 4 klien (40\%), SMP 3 klien (30\%) dan SMA 3 klien (30\%).

Rata-rata umur responden masing- masing kelompok adalah kelompok I rata-rata umur 46,1 tahun, kelompok II, 44.4 tahun dan kelompok III 42.2 tahun.

Hasil analisis mual muntah klien sebelum pemberian minuman dingin $10-15^{\circ}$ adalah dengan nilai rata-tara 5.93 dan standar deviasi 0,994 . Jumlah mual muntah pre terendah adalah 4 dan jumlah mual muntah pre tertinggi adalah 7 . Hasil analisis mual muntah klien setelah pemberian minuman dingin $10-15^{\circ}$ memiliki nilai rata-rata 1.43 dan standar deviasi 0.728 . Jumlah 
mual muntah post terendah adalah 1 dan jumlah mual muntah post tertinggi adalah 3 .

\section{B. ANALISIS BIVARIAT}

Normalitas data merupakan asumsi pertama yang harus dipenuhi. Pengujian asumsi ini dilakukan pada data mual muntah sebelum dan sesudah pemberian minuman dingin 10$15^{\circ} \mathrm{C}$. Salah satu cara untuk mengetahui terpenuhinya asumsi ini adalah dengan nilai skewness. Hasil pengujian asumsi normalitas data memperlihatkan bahwa data sebelum dan sesudah berdistribusi normal, karena nilai skewnes <-2 atau 2. Maka, analisis bivariat dilakukan dengan uji parametrik, yaitu paired sample t-test, an untuk menganalisis hubungan antara kelompok perlakuan menggunakan statistik uji Anova.

Hasil uji statistik pemberian minuman es teh manis dingin $10-15^{\circ} \mathrm{C}$ menunjukkan nilai $\mathrm{t}=15.667$ dan hasil uji statistik nilai $p$ value $=0,000$. Hal ini berarti pada alpha $5 \%$ terlihat pemberian minuman es teh manis dingin $10-15^{\circ} \mathrm{C}$ memiliki pengaruh terhadap penurunan sensasi mual muntah klien dimana terdapat perbedaan yang signifikan antara nilai rentang mual muntah pre dengan mual muntah post.

Hasil uji statistik pemberian minuman jus melon dingin $10-15^{\circ} \mathrm{C}$ menunjukkan nilai $\mathrm{t}=12.075$ dan hasil uji $p$ value $=0,000$. Hal ini berarti pada alpha $5 \%$ terlihat pemberian minuman jus melon dingin $10-15^{\circ} \mathrm{C}$ memiliki pengaruh terhadap penurunan sensasi mual muntah klien dimana terdapat perbedaan yang signifikan antara nilai rentang mual muntah pre dengan mual muntah post.

Hasil uji statistik pemberian minuman es susu dingin $10-15^{\circ} \mathrm{C}$ menunjukkan nilai $\mathrm{t}=-5.449$ dan hasil uji $p$-value $=0,000$. Berarti pada alpha $5 \%$ pemberian minuman es susu dingin $10-15^{\circ} \mathrm{C}$ memiliki pengaruh terhadap penurunan sensasi mual muntah klien dimana terdapat perbedaan yang signifikan antara nilai rentang mual muntah pre dengan mual muntah post.

Hasil uji statistik rata-rata mual muntah pre dan post pemberian minuman dingin $10-15^{\circ} \mathrm{C}$ dapat dilihat pada masing-masing kelompok perlakuan. sehingga dapat disimpulkan tidak ada perbedaan yang signifikan mual muntah pre dan post pemberian minuman dingin $10-15^{\circ} \mathrm{C}$ diantara masing-masing kelompok perlakuan tersebut.

\section{PEMBAHASAN}

\section{Distribusi Tingkat Pendidikan}

Distribusi tingkat pendidikan masingmasing kelompok intervensi, paling banyak responden berpendidikan SD. Hal ini menunjukkan adannya kecenderungan bahwa semakin tinggi tingkat pendidikannya semakin baik tingkat pengetahuannya.

Hasil ini sesuai dengan teori yang ditulis oleh Notoadmojo (2003) yaitu semakin tinggi tingkat pendidikan seseorang maka ia akan mudah menerima hal-hal baru dan mudah menyesuaikan dengan hal yang baru tersebut. Tingkat pendidikan mempengaruhi perilaku dan menghasilkan banyak perubahan, khususnya pengetahuan di bidang kesehatan. Menurut peneliti, semakin tinggi tingkat pendidikan formal semakin mudah menyerap informasi termasuk juga informasi kesehatan, semakin tinggi pula kesadaran untuk berperilaku hidup sehat. Untuk masing- masing kelompok tingkat pendidikan klien tidak mempunyai pengaruh signifikan terhadap pembrian minuman dingin.

Hasil penelitian ini didukung oleh penelitian Widiawati N, (2013) Hubungan tingkat pendidikan formal dan tingkat pengetahuan wanita tentang kanker payudara dengan kejadian kanker payudara di borokulon banyuurip purworejo, dengan hasil menunjukkan bahwa terdapat hubungan yang positif antara tingkat pendidikan formal dengan tingkat pengetahuan wanita tentang kanker payudara. Semakin tinggi tingkat pendidikan maka semakin tinggi tingkat pengetahuannya. Adanya hubungan antara tingkat pendidikan dengan tingkat pengetahuan wanita mengenai kanker payudara.

\section{Distribusi Umur Responden}

Distribusi rata-rata umur responden masing-masing kelompok adalah kelompok I rata-rata umur klien 46.1 tahun, kelompok I ratarata umur klien 44.4 tahun dan kelompok III rata-rata umur klien 42.2 tahun.

Hal ini sesuai dengan teori Wijaya (2005), pada umumnya makin tua usia kita, makin tinggi resiko terkena kanker payudara. Setiap resiko kanker payudara pada wanita dapat mempunyai kemungkinan yang lebih tinggi atau lebih rendah, tergantung pada beberapa faktor yang meliputi riwayat keluarga, genetik, usia menarche dan faktor-faktor lain. Ketika wanita dengan usia muda terkena kanker payudara, maka ada kecenderungan perkembangan kanker tersebut lebih agresif dibanding wanita dengan usia yang 
lebih tua. Hal ini yang menjelaskan mengapa angka harapan hidup pada wanita usia muda lebih rendah dari pada wanita yang usianya lebih tua. Dimana angka harapan hidup berdasarkan usia ditemukannya kanker payudara: usia $<45$ tahun memiliki harapan hidup 81\%, usia 45-64 tahun memiliki harapan hidup sekitar $85 \%$ dan usia 65 tahun atau lebih sekitar $86 \%$.

Hasil penelitian ini didukung penelitian Simanjuntak (1977) yang telah melakukan penelitiannya di Bagian Bedah FKUI/RSCM periode 1971-1973, menemukan beberapa faktor penyebab kanker payudara yang sudah diterima secara luas kalangan pakar kanker (Oncologist) di dunia, salah satunya adalah wanita yang berumur lebih dari 30 tahun mempunyai kemungkinan yang lebih besar untuk mendapat kanker payudara dan resiko ini akan bertambah sampai umur 50 tahun dan setelah menopause.

\section{Karakteristik mual muntah sebelum (pre) dan sesudah (post) pemberian minuman dingin.}

Karakteristik mual muntah sebelum (pre) dan sesudah (post) pemberian minuman dingin $10-15^{\circ} \mathrm{C}$. Diketahui bahwa jumlah mual muntah sebelum pemberian minuman dingin $10-15{ }^{\circ} \mathrm{C}$ terendah adalah 4 dan tertinggi adalah 7 . Dan diketahui jumlah mual muntah setelah pemberian minuman dingin $10-15{ }^{\circ} \mathrm{C}$ terendah adalah 1 dan tertinggi adalah 3 .

Data tersebut sesuai dengan teori, bahwa mual muntah yang terjadi setelah dilakukan kemoterapi dikenal sebagai Chemotherapy Induced Nausea and Vomiting (CINV), dimana nausea dan vomiting yang tidak terkontrol dapat mempengaruhi terapi pada klien secara keseluruhan dan mempengaruhi respon terapi serta menurunkan tingkat kesembuhan klien kanker. Selain itu mual muntah yang tidak terkontrol juga dapat menyebabkan dehidrasi, etidakseimbangan elektrolit, penurunan berat badan, dan malnutrsisi. (Pazdur, 2003). Klien dengan kanker payudara yang menjalani kemoterapi, akan terstimulasi oleh toksin kemoterapi sehingga merangsang pusat muntah pada Cemoreseptor trigger zone (CTZ), hal ini dapat meningkatkan ketegangan dan kecemasan yang menstimulus traktus gastrointestinal untuk memperberat rasa mual muntah yang timbul setelah kemoterapi.

Hasil penelitian ini didukung oleh penelitian Rahmah, SD (2008) tentang evaluasi penggunaan obat anti muntah pada klien retinoblastoma yang menjalani kemoterapi di Rumah Sakit Kanker Darmais. Data didapatkan dari lembar kemoterapi dalam rekam medis secara retrospektif dan dianalisa dengan metode desktiptif non analitik dengan menggunakan chisquare test, dan didapatkan hasil bahwa pada pasien yang menerima antiemetik sebelum kemoterapi yang sesuai berdasarkan potensial emetik agen kemoterapi yang didapat sebesar $23.81 \%$. Pasien yang masih mengalami muntah sebesar $61.54 \%$

Terapi nonfarmakologi berupa pemberian minuman dingin lebih cepat diserap dalam tubuh dari pada air hangat dan akan membantu rehidrasi, sehingga dapat mengupayakan klien agar merasa segar, membuka nafsu makan dan secara sadar dapat mengendalikan aktivitas faal dan psikis, memperbaiki kondisi disfungsi faal/ psikis, sehingga berhasil menstabilkan emosi dan mengatasi gejala mual muntah setelah kemoterapi.

Minuman dingin dapat memiliki peran untuk memberikan kesegaran tubuh dan membuka nafsu makan (Admin, 2012). Menggugah nafsu makan pada klien kanker, dalam mengatasi efek nafsu makan akibat kemoterapi yaitu dengan memilih makanan yang dingin, manis dan tidak beraroma. Biasanya dimulai dengan makanan yang dapat merangsang nafsu makan seperti es krim atau pop ice atau dengan tips memulai makan dengan makanan atau minuman yang dingin (Cristanto. E, 2012). Menurut peneliti dengan pemberian minuman dingin, merupakan tindakan yang mudah untuk diajarkan kepada klien dalam rangka meningkatkan kemandirian klien dalam mengatasi masalah kesehatannya yaitu mual muntah setelah kemoterapi, secara non farmakologik. Perawat sangat berperan dalam memfasilitasi kemandirian klien, dan sesuai dengan konsep yang dikemukakan oleh Orem tentang Self Care.

Menurut teori self-care Orem, klien dipandang sebagai individu yang memiliki potensi positif untuk merawat dirinya sendiri untuk memenuhi kebutuhan hidup, memelihara kesehatan dan mencapai kesejahteraan. Klien dapat mencapai sejahtera/kesehatan yang optimal apabila mengetahui perawatan yang tepat dan sesuai dengan kondisi dirinya sendiri. Oleh karena itu, perawat menurut teori self-care berperan sebagai pendukung /pendidik bagi klien (Tomey \& Alligood, 2006). 


\section{Karakteristik mual muntah pre dan post masing-masing kelompok perlakuan terhadap pemberian minuman dingin}

Karakteristik mual muntah pre dan post masing-masing kelompok perlakuan terhadap pemberian minuman dingin $10-15^{\circ} \mathrm{C}$. Hasil uji statistik kelompok intervensi I (es teh manis), kelompok intervensi II (jus melon) dan kelompok intervensi III (es susu nutrican) menunjukkan nilai $p$ value $=0,000$.

Masing-masing kelompok memiliki pengaruh terhadap penurunan sensasi mual muntah klien dimana terdapat perbedaan yang signifikan antara nilai rentang mual muntah pre dengan mual muntah post. Hal ini berarti makanan/minuman dingin seperti buah, jus buah,susu, teh manis atau makanan/minuman dingin sejenisnya dapat diberikan pada suhu mencapai $10-15{ }^{\circ} \mathrm{C}$ (Prabu,2009). Penggantian air yang adekuat selama mual/muntah sangat penting untuk memelihara penampilan yang optimal dan memelihara kesehatan. Air dingin kira-kira $10{ }^{\circ} \mathrm{C}$ lebih baik dari pada air hangat. Oleh karena air dingin lebih cepat diserap oleh usus, sehingga waktu pengosongan lambung lebih cepat (Primana, DA. 2013).

Menurut peneliti mual muntah yang terjadi pada klien setelah kemoterapi disertai rasa cemas dan ketegangan sehingga dengan minuman dingin dapat memberikan kesegaran dan memberikan rasa nyaman pada perut.

Berdasarkan kategori bantuan kebutuhan Self Care pada masalah yang berkaitan dengan masalah nutrisi pada klien kanker terutama untuk mengatasi mual muntah, dapat diberikan dengan kategori 1) Partially Compensatory, bantuan ini diberikan sebagian, dibutuhkan bagi klien yang mengalami keterbatasan gerak karena sakit atau kecelakaan. Dalam hal ini klien mengalami kondisi yang lemah akibat mual muntah, klien tidak mampu bangun ataupun duduk sendiri dari tempat tidur. 2) supportive Education bantuan diberikan dengan memberikan dukungan pendidikan dibutuhkan oleh klien yang memerlukannya untuk dipelajari, agar mampu melakukan perawatan mandiri (Orem's 1980). Dalam hal ini, perawat membantu dan mengajarkan cara membuat minuman dingin 10$15^{\circ} \mathrm{C}$ pada klien yang mengalami mual muntah akibat kemoterapi, dengan kondisi klien mampu bangun dan duduk sendiri dari tempat tidur dan mampu melakukan sendiri dalam mengatasi mual muntahnya.

Selisih rata-rata mual muntah pre dan mual muntah post diantara ke tiga jenis minuman, adalah es teh manis (4.70), jus melon (4.50) dan es susu nutrican (4.30). Nilai selisih rata-rata mual muntah pre dan mual muntah post paling rendah adalah es susu nutrican.

Nutrican adalah suatu produk nutrisi (dalam bentuk bubuk/susu) bagi yang menderita sakit kronis seperti kanker. Nutrican juga merupakan makanan diet khusus yang diformulasikan untuk menunjang perbaikan kondisi klien kanker yang cenderung kehilangan nafsu makan dan mengalami penurunan berat badan terus-menerus dan dapat dikonsumsi sebagai makanan pelengkap maupun makanan pengganti sebelum, selama, maupun sesudah menjalani terapi sesuai dengan kebutuhan klien dan petunjuk dokter/ahli gizi. Dimana susu bukan hanya baik dalam kandungan nutrisi, susu juga memiliki manfaat lain, terutama jika diminum dalam keadaan dingin (Ekowati.H, 2013).

Nutrien dalam susu tingkat kecernaannya tinggi karena merupakan bahan organik, susu dapat memenuhi nutrisi tubuh sampai $60 \%$, tingkat kecernaan susu butuh waktu sekitar 2-3 jam untuk dicerna. Sedangkan kandungan serat dan air pada buah melon dapat membantu melancarkan pencernaan, selain segar dan bisa membuat tubuh tetap terhidrasi karena kandungan airnya, sistem pencernaan bisa menjadi lebih lancar (Noorwati.S, 2006 dalam Sudoyo et al).

Menurut peneliti berdasarkan wawancara responden (kelompok intervensi III), responden mengatakan sangat jarang minum susu karena tidak terbiasa, harga susu mahal tidak terjangkau dengan pendapatan yang diperoleh. Sedangkan untuk es teh manis, minuman yang sudah menjadi vaforit banyak orang, mudah didapat dan dibuat, aromanya tidak membuat mual, serta harga terjangkau. Dan jus melon selain banyak mengandung air yang dapat menyegarkan, terutama dipropinsi lampung banyak petani membudidayakan tanaman buah melon sehingga mudah didapat.

Minuman es teh manis telah terbukti menjadi salah satu minuman sehat, menambah imunitas untuk menjaga tubuh tetap sehat dan menjadi minuman favorit banyak orang, es teh mengandung beberapa antioksidan yang dapat menangkap radikal bebas dalam tubuh, adanya Polifenol pada teh berupa katekin dan flavanol yang mampu mencegah sel kanker tumbuh dari dalam tubuh, menurunkan kadar kolesterol, serta gula dalam darah, mengandung vitamin $\mathrm{C}$ dalam teh berfungsi sebagai antioksidan dan meningkatkan daya tahan tubuh (Hidayat.F., 2013).

Hasil penelitian ini sesuai dengan teori (Bahatori D, 2013) minuman dingin secara umum bermanfaat untuk merespon tubuh 
menimbulkan mekanisme vasoconstriction atau penyempitan pembuluh darah. Dimana penyempitan pembuluh darah ini merupakan mekanisme tubuh untuk menjaga agar tidak terjadi pengeluaran kalori berlebihan dari tubuh, sehingga tubuh tidak perlu mengalami penurunan suhu atau hipotermia. Tujuan perawatan melalui terapi nonfarmakolagik dengan pemberian minuman dingin merupakan salah satu cara pengelolaan diri yang didasarkan pada cara kerja sistem syaraf simpatis dan parasimpatis.

Sistem kerja saraf manusia yang terdiri dari sistem saraf pusat dan sistem saraf otonom. Sistem saraf pusat berfungsi mengendalikan gerakan-gerakan yang dikehendaki, misalnya reaksi tubuh terhadap suhu dingin (minuman dingin), seperti saraf-saraf disekitar mulut, tenggorokan sampai perut bagian atas akan terangsang secara mendadak. Sebaliknya, sistem saraf otonom berfungsi mengendalikan gerakangerakan yang otomatis (self governing), misalnya otot-otot halus, proses kardiovaskuler, dan aktivitas berbagai kelenjar dalam tubuh .

Sistem saraf otonom ini terdiri dari dua subsistem yaitu sistem saraf simpatis dan sistem saraf parasimpatis yang kerjanya saling berlawanan. Sistem saraf simpatis lebih banyak aktif ketika tubuh membutuhkan energi. Misalnya pada saat terkejut, takut, cemas, atau berada dalam keadaan tegang, dimana kondisi ini dapat terjadi pada saat mual/muntah. Pada kondisi seperti ini, sistem syaraf akan memacu aliran darah ke otot-otot skeletal, meningkatkan detak jantung dan kadar gula. Sebaliknya, system saraf parasimpatetis mengontrol aktivitas yang berlangsung selama penenangan tubuh, misalnya penurunan denyut jantung setelah fase ketegangan dan menaikkan aliran darah ke sistem gastrointestinal (Carlson, 1994, dalam Ramdhani \& Putra, 2008). Pemberian minuman dingin seperti es teh, jus buah,es susu atau minuman dingin sejenisnya dapat menimbulkan mekanisme vasokontriksi, sehingga merangsang syaraf simpatis dari stimulasi reseptor gastrointestinal yang menimbulkan refleks nyaman sehingga rangsangan kedalam cortex menurun dan hypothalamus menyampaikan rangsangan kepusat muntah menjadi menurun.

Hasil penelitian ini menunjukan frekuensi mual muntah menurun setelah pemberian minuman dingin $10-15^{\circ} \mathrm{C}$, yaitu frekuensi mual muntah menjadi berkurang dari rata-rata mual muntah sebelum pemberian minuman dingin adalah 4-7 kali dan setelah pemberian minuman dingin rata-rata mual muntah menjadi 1-3 kali, disertai kebiasan makan klien tidak berubah, asupan makan bertambah dan asupan kalori dan cairan memadai. Sesuai dengan tujuan keperawatan model Orem's secara umum, yaitu 1) Menurunkan tuntutan self care kepada tingkat dimana klien dapat memenuhinya, ini berarti menghilangkan self care deficit. Dimana kebutuhan nutrisi klien dapat terpenuhi karena mual muntah berkurang atau hilang dengan pemberian minuman dingin $10-15^{\circ} \mathrm{C}$. 2) Memungkinkan klien meningkatkan kemampuannya untuk memenuhi tuntutan self care.

Klien dapat melakukan pemberian minuman dingin $10-15^{\circ} \mathrm{C}$ secara mandiri. 3) Memungkinkan orang yang berarti (bermakna) bagi klien untuk memberikan asuhan dependent (dependent care). Keluarga atau orang terdekat klien dapat berperan membantu kebutuhan klien mengatasi mual muntah dengan minuman dingin $10-15^{\circ} \mathrm{C}$ atau perawat secara langsung dapat memenuhi kebutuhan-kebutuhan self care klien (Orem's, 1980). Hasil penelitian ini didukung oleh Hudayati F. (2013) tentang Gangguan makan pasca kemoterapi dan radiasi, untuk mengatasi masalah gangguan nafsu makan akibat mual muntah salah satunya dengan makanan/ minuman dingin. Pemberian minuman dingin merupakan salah satu cara pengelolaan diri yang didasarkan pada cara kerja sistem syaraf simpatis dan parasimpatis ini.

Menurut Ekowati. H. (2013) tentang kesehatan dan pendamping pasien kanker, mengkonsumsi jus 6xsehari, saat sakit kebutuhan tubuh sangat jauh lebih besar dari pada kebutuhan tubuh dalam keadaan sehat janganlah takut kelebihan dosis karena zat alam yang terkandung dalam jus berbentuk provitamin. Didalam tubuh, provitamin sesuai kebutuhan sisanya disimpan dalam hati. Untuk perawatan dirumah teratur minum obat dan komplementer minum curzema dan susu nutrican wajib dijalani sesuai dengan protocol medis, konsultasi dengan dokter tentang pengobatan komplementer, oleh karena itu pengobatan medis yang utama dan komplementer tidak menimbulkan reaksi yang bertentangan.

Perawat berperan sebagai pendidik dengan mengajarkan tindakan pemberian minuman dingin dalam penelitian ini menggunakan minuman es teh manis, jus melon dan es susu (nutrican) dingin $10-15^{\circ} \mathrm{C}$ untuk membantu klien pengidap kanker payudara sehingga mampu mengatasi masalah mual dan muntah setelah kemoterapi, dan dapat tetap mempertahankan kemampuan optimalnya dalam mencapai kesejahteraan hidup. Orem (dalam Tomey \& Alligood, 2006), bahwa perawatan sendiri adalah suatu kebutuhan universal untuk menjaga dan meningkatkan eksistensi dirinya, kesehatan dan 
kesejahteraan hidupnya. Oleh karena itu, perawat sebaiknya membantu klien untuk mencapai kemampuan dalam perawatan diri, dalam rangka menjalankan perannya sebagai pendidik.

\section{SIMPULAN}

1. Tingkat pendidikan responden masingmasing kelompok intervensi , paling banyak berpendidikan SD .

2. Hasil uji statistik nilai $p$-value $=0,000$. terlihat pemberian minuman es teh manis, jus melon dan es susu dingin $10-15^{\circ} \mathrm{C}$

\section{DAFTAR PUSTAKA}

Admin. 2012. Meningkatkan nafsu makan setelah kemoterapi. http://kemoterapi.co.id/index,php/tag/kemo terapi(Diunduh tanggal 14 Februari 2015).

Bahatori, D. 2013. Manfaat minuman dingin. http://www.semyceper.blogspot.com (Diunduh tanggal 16 Februari 2015).

Christianto,E. 2012. Menggugah nafsu makan pasien kanker. http://siapapunsehat.blogspot.com (Diunduh tanggal 14 februari 2015).

Depkes. $2006 . \quad$ Manajemen. http://www.depkes.co.id/index.html (Diunduh tanggal 26 Januari 2015).

Ekowati. 2013. Kesehatan dan pendamping pasien kanker. http://www.pinterestkesehatan (Diunduh tanggal 26 Januari 2015).

Hawari, D.H. 2004. Psikiater Kanker Payudara, Dimensi Psikoreligi. Jakarta: Balai Penerbit FKUI.

Hudayati. 2013. Gangguan makan pasca kemoterapi dan radiasi. http://www.shutterstock.com (Diunduh tanggal 14 Februari 2015).

Mc Donald, J.M. 2001. The Effect of Music on Chemotherapy-Induced Nausea, Vomiting and Retching. Disertasi pada California State University. Diunduh dari http://www.proquest.com (tangggal 16 February 2015).

Noorwati. 2006. Terapi nutrisi pada pasien kanker. Dalam Sudoyo Et all. Buku Ajar Ilmu Penyakit Dalam. Edisi IV.Pusat Penerbitan Departemen Ilmu Penyakit Dalam FKUI. Jakarta ; hal 846-848

Notoatmodjo, S. 2002. Metodologi penelitian kesehatan. Jakarta: Rineka Cipta memiliki pengaruh terhadap penurunan sensasi mual muntah klien, terdapat perbedaan yang signifikan antara nilai rentang mual muntah pre dengan mual muntah post.

3. Diketahui selisih nilai rata-rata mual muntah sebelum (pre) dan setelah (post) pemberian minuman dingin $10-15^{\circ} \mathrm{C}$ diantara ke tiga kelompok perlakuan adalah es susu (nutrican) yang memiliki nilai selisih ratarata paling rendah, karena nutrien dalam susu tingkat kecernaannya tinggi, tingkat kecernaan susu butuh waktu sekitar 2-3 jam untuk dicerna.
Notoatmodjo, S. 2003.Pendidikan dan Perilaku Kesehatan. Jakarta: Rineka Cipta.

Pazdur. 2003. Chemotherapy Induced Nausea and Vomiting (CINV), A Complete Guide to Combination Chemotherapy Regimen3rd edition. Coria.Lexy Comp Inc.

Pollit, D.F., \& Beck, C.T. 2006. Essentials of Nursing Research: Methods, Appraisal, and Utilization (6th Ed.). Philadelphia: Lippincott Williams \& Walkins.

Prabu, P. 2009. Penyimpanan Bahan Makanan (Prinsip Food Hyegiene). https:// putraprabu.wordpress.com/2009/01/05/pen yimpanan bahan-makanan-prinsipfood-hygiene/ (Diunduh tanggal 6 Februari 2015).

Primana, D. A. 2013. Kebutuhan Air dan Elektrolit. Bagian Ilmu Gizi FK Unpad Healthy Articles; http://www.smalcrab.com/kesehatan/597/kebutuhan-air-dan-elektrolit (Diunduh tanggal 4 februari 2015).

Rahmah, SD. 2008. Evaluasi penggunan obat anti muntah pada klien retinoblastoma yang menjalani kemoterapi di rumah sakit kanker darmais. Laporan Penelitian. Jakarta: FKUI. http:www//stylecraze.com (Diunduh pada tanggal 20 Februari 2015).

Ramdhani, N., \& Putra, A. A. 2008. Pengembangan Multi Media Relaksasi. Laporan Penelitian. Yogyakarta: Fakultas Psikologi UGM. http://neila.staff.ugm.ac.id/wordpress/wpcontent/uploads/2008/05/relaksasi otot. Pdf (Diunduh tanggal 20 Februari 2015).

Sastroasmoro, S., \& Ismail, S. 2011. DasarDasar Metodologi Penelitian Klinis. Edisi_4. Jakarta : CV Sagung Seto. 
Tomey, M.A., \& Alligood, M.R. 2006. Nursing Science and Their Works. 6th Ed. St.Louis; Mosby.

Widiawaty, N. 2012. Hubungan Tingkat Pendidikan Formal dan Tingkat Pengetahuan Wanita Tentang Kanker Payudara dengan Kejadian Kanker
Payudara di Borokulon Banyuurip Purworejo. $\quad$ http://e-journal.akbidpurworejo.ac.id/index.php/jkk3/article/vie w/57 (Diunduh tanggal 02 Agustus 2015). Wijaya. 2005. Mengenal Kanker Payudara, http://www.fortunestar.co.id/content/view/ (Diunduh tanggal 23 Maret 2013). 